\title{
GREGÓRIO DE MATOS, NOSSO PRIMEIRO ANTROPÓFAGO
}

\author{
Samuel Anderson de Oliveira Lima* \\ Universidade Federal do Rio Grande do Norte
}

Resumo: A figura exponencial de Gregório de Matos tem sido, ao longo dos anos, motivo de muitas discussões teóricas. Nesse panorama, ainda existem dois lados antagônicos quando se trata da poesia de Gregório de Matos, os que o defendem e os que o acusam. Os primeiros defendem a posição de que o poeta baiano foi a primeira voz literária no Brasil alçada sob as bases do Barroco, e os outros o acusam de ser ele um mero imitador dos poetas espanhóis do século XVII, sem, portanto, ter contribuído significativamente para a formação da Literatura Brasileira. Este artigo, que é fruto de uma pesquisa de doutoramento, segue o pensamento daqueles que defendem o poeta como barroco-antropofágico, devorador de culturas, com participação ativa no processo de formação da nossa identidade cultural e literária. Ancorado pelo pensamento crítico dos irmãos Campos, nosso trabalho busca observar e discutir a hipótese de que Gregório de Matos foi nosso primeiro antropófago, sendo possível enxergar em seus poemas as características intrínsecas do movimento antropofágico, idealizado por Oswald de Andrade no século XX.

Palavras-chave: Antropofagia. Gregório de Matos. Barroco.

\section{Introdução}

Em 1974, Augusto de Campos afirmava que nosso primeiro antropófago foi Gregório de Matos, o poeta que devorou a cultura europeia, sabendo digeri-la para ressignificar a nossa identidade, "o primeiro antropófago experimental/da nossa poesia" (CAMPOS, 1986, p. 90). É Gregório quem sabiamente inicia a festa antropofágica, devorando, muitas vezes, a palavra do pai, transformando-a noutro discurso, destituído da oficialidade, transgressora, por vezes, enigmática. Como num baile de máscaras barroco, Gregório vai construindo um labirinto, com percursos tortuosos, fechado, mas festivo. Vale ressaltar, neste contexto, que Gregório de Matos não tinha a intenção consciente de ser antropofágico nos termos da devoração cultural, mas ele antecipa o movimento idealizado por Oswald de Andrade que será marca de sua investida modernista. Portanto, nosso objetivo,

\section{Esta obra está licenciada sob uma Creative Commons - Atribuição 4.0}

\footnotetext{
* Mestre e doutor em Estudos da Linguagem/UFRN, área de concentração em Literatura Comparada. Professor Adjunto II do Departamento de Línguas e Literaturas Estrangeiras Modernas e do Programa de Pós-Graduação em Estudos da Linguagem da UFRN. E-mail: <sanderlima25@yahoo.com.br>.
}

Anu. Lit., Florianópolis, v. 21, n. 1, p. 46-57, 2016. ISSNe 2175-7917 
neste artigo, é discutir a assertiva de Augusto de Campos sobre a configuração antropofágica do poeta baiano, partindo das premissas elaboradas por Oswald de Andrade em seu Manifesto Antropófago, passando pelo pensamento teórico de Haroldo de Campos que ratifica a palavra de seu irmão, até confluir nos poemas que exemplificarão as afirmações aqui expostas.

\title{
Antropofagia tropical
}

Acertadamente, Haroldo de Campos (2010, p. 209) considera que "GM soube levar a mistura de elementos do Barroco à própria textura de sua linguagem, através da miscigenação idiomática de caldeamento tropical”. O Barroco brasileiro é a imagem desse discurso de Haroldo de Campos. O transplante do Barroco para a América provocou essa mistura na linguagem. A viagem pelo Atlântico admitiu ao Barroco ser perfurado pelo intenso jogo tropical da abundância das frutas, das paisagens, das flores.

Em Gregório de Matos, seu texto poético traz traços dessa miscigenação cultural, na tradução do processo antropofágico, como "uma civilização que estamos comendo, porque somos fortes e vingativos como o jabuti” (ANDRADE, 1978, p. 17). Como exemplo da devoração linguística, o poema que se segue já a indica na didascália "Disparates na língua brasílica a huma cunhaã, que ali galanteava por vicio":

\author{
Indo à caça de tatus \\ encontrei Quatimondé \\ na cova de um jacaré \\ tragando trezes Teiús: \\ eis que dous Surucucus \\ como dous Jaratacacas \\ vi vir atrás de umas Pacas, \\ e a não ser um Preá \\ creio, que o Tamanduá \\ não escapa às Gebiracas. \\ De massa um tapiti, \\ um cofo de Sururus, \\ dous puçás de Baiacus, \\ Samburá de Murici: \\ Com uma raiz de aipi \\ vos envio de Passé, \\ e enfiado num imbé \\ Guiamu, e Caiaganga, \\ que são de Jacaracanga \\ Bagre, timbó, Inhapupê. \\ Minha rica Cumari, \\ minha bela Camboatá \\ como assim de Pirajá \\ me desprezas tapiti:
}


não vedes, que murici

sou desses olhos timbó

amante mais que um cipó

desprezado Inhapupê,

pois se eu fora Zabelê

vos mandara um Miraró. (MATOS, 1999, p. 863-864)

Esse poema serve para observarmos a linguagem antropofágica de devoração presente nos versos. O poema traz elementos (vocábulos) que nos remetem especialmente à linguagem indígena, do ameríndio. A devoração, nesses versos, está associada à assimilação dos valores culturais dos índios, uma vez que Gregório de Matos se alimenta da cultura indígena, praticando a mestiçagem textual, isto é, promovendo um caldeamento tropical. Segundo Haroldo de Campos (2010, p. 209) Gregório tem o "mesmo hibridismo que se encontra no nosso barroco plástico". Essa mistura dos vocábulos portugueses e tupis é a representação da antropofagia oswaldiana, no sentido de que há uma amalgamação, uma miscigenação entre as línguas, que nem é mais portuguesa nem tupi-guarani, por isso, Evando Nascimento (2011, p. 331) afirma que "a devoração real ou metafórica acarreta a morte do outro". Nesse sentido, devorar aqui é sinônimo de destruir, mas uma destruição que é também reconstrução, pois o sujeito devorado agora faz parte do corpo do que devorou, como na Eucaristia, em que o corpo de Cristo é transubstanciado a fim de ser vida no corpo dos fiéis. Assim como o rito antropofágico, Gregório também é seletivo, e como poeta ele sabe que termos escolher, que expressões usar. Evando Nascimento (2011, p. 338) ainda considera sobre o processo de devoração antropofágica: "o que nos identifica é o selo da deglutição do outro civilizado", lembrando a data da morte do bispo Sardinha pelos canibais brasileiros. Sob este aspecto, o poeta Gregório de Matos é quem primeiro promove em solo brasileiro a absorção dos valores do outro, não sem razão foi considerado o primeiro antropófago.

\section{O ritual antropofágico}

O ritual antropofágico, num ato desmedido de devoração, instaura no cenário brasileiro o resgate daquilo que formaria nossa identidade como povo, como gente. Gregório é o príncipe que retoma seu trono perdido no século XVII e renova as forças desmistificantes do substrato apoteótico da palavra, ele é a parte perdida do todo que foi achada pelo século XX. O objetivo da antropofagia rezado por Oswald de Andrade era "resgatar os valores nacionais para divulgá-los em todo o mundo, fazendo com que o europeu aceitasse a cultura estrangeira não apenas pela perspectiva excêntrica, mas pelos critérios da diferença e da autenticidade" (BITARÃES NETTO, 2004, p. 63) e Gregório foi o porta-bandeira desse pensamento, o 
primeiro antropófago barroco-brasileiro.

O interesse da metáfora antropófaga se concentra no outro - eu mordo o que posso -, devora-se o outro. Nesse sentido, a primeira frase do Manifesto Antropófago "a antropofagia nos une" demonstra esse pensamento de que o que me interessa é o outro e não aquilo que é meu, ao contrário, "só me interessa o que não é meu”. Por isso, conclui João Almino (2011, p. $55)$ :

A cultura brasileira não é, portanto, insular e voltada unicamente para suas raízes, para o solo nacional, [...] nem, por outro lado, se insere, de forma secundária ou subordinada, numa civilização universal centrada na Europa. Está não apenas aberta ao outro, mas preparada para devorá-lo.

Essa é uma ideia altamente coerente com aquilo que pregou Oswald de Andrade em seu Manifesto, pois descarta o que se diz sobre o nacionalismo ufanista apregoado nas malhas da modernidade. O movimento de vanguarda no Brasil surgiu a partir de uma viagem de Oswald de Andrade à Europa, que ali foi influenciado pelas ideias futuristas. O Brasil, nesse sentido, realizou o processo de imitação, que se compara ao ato antropofágico de devoração como nos ritos canibais. Oswald foi antropófago mesmo antes de produzir o Manifesto. Foi devorando o outro, absorvendo-lhe o melhor que a Europa tinha para ruminar aqui no Brasil. Essa é a razão pela qual Gregório de Matos é considerado o nosso primeiro antropófago, pois devorou a cultura do outro (Gregório de Matos era simultaneamente o outro e ele mesmo, devorando e devorando-se) para regurgitá-la aqui, formando a cultura brasileira. Quando o Modernismo se volta para o passado na busca da origem de nossa identidade, o faz pelo processo antropofágico, sendo o poeta baiano a expressão antropofágica brasileira. Rever o passado significa digeri-lo na tentativa de assimilar o outro que há nele. Nessa perspectiva, considera Viviana Gelado (2006, p. 32): "praticar a antropofagia cultural é digerir simbolicamente a tradição cultural para poder ser capaz de ultrapassar o modelo que ela impõe e criar, a partir de uma atitude criativa e dessacralizadora, um modelo próprio [...]”.

A teoria da antropofagia em si aponta para o rito canibal ${ }^{1}$ de devoração do inimigo,

\footnotetext{
${ }^{1}$ Um dos autores que influenciam diretamente Oswald de Andrade para a formulação do Manifesto Antropófago foi Michel de Montaigne. O ensaísta francês, num ensaio chamado "Sobre os Canibais", vai discorrer sobre o mau selvagem, o homem que vivia do outro lado do Atlântico, o canibal. A partir de relatos sobre essa terra e sobre seus habitantes, Montaigne conclui que eles nada têm de bárbaros, "acho que não há nada de bárbaro e de selvagem nessa nação", pensa assim porque ser bárbaro é ser alheio aos costumes do outro, e nesse sentido, os europeus também poderiam ser considerados bárbaros desde o campo de visão dos canibais. E baseado nesse pensamento, o ensaísta defende o canibal considerando que não há diferença em comer um vivo de comê-lo morto, isto é, faz uma crítica para as atrocidades das guerras, das torturas inquisitoriais, etc.: "penso que há mais barbárie em comer um homem vivo do que em comê-lo morto, em dilacerar por tormentos e suplícios um corpo ainda cheio de sensações, fazê-lo assar pouco a pouco, fazê-lo ser mordido e esmagado pelos cães e pelos porcos (como não apenas lemos mas vimos de fresca memória, não entre inimigos antigos, mas entre vizinhos e
} 
realizado não como produto da fome, mas como representação metafórica da absorção da força, do poder. O uso do canibalismo para explicar a antropofagia foi indigesto para a sociedade da época porque relembrava o ato de comer a carne humana. A intenção era esta: provocar estranhamento. Num outro poema gregoriano, o poeta faz menção ao rito canibalesco:

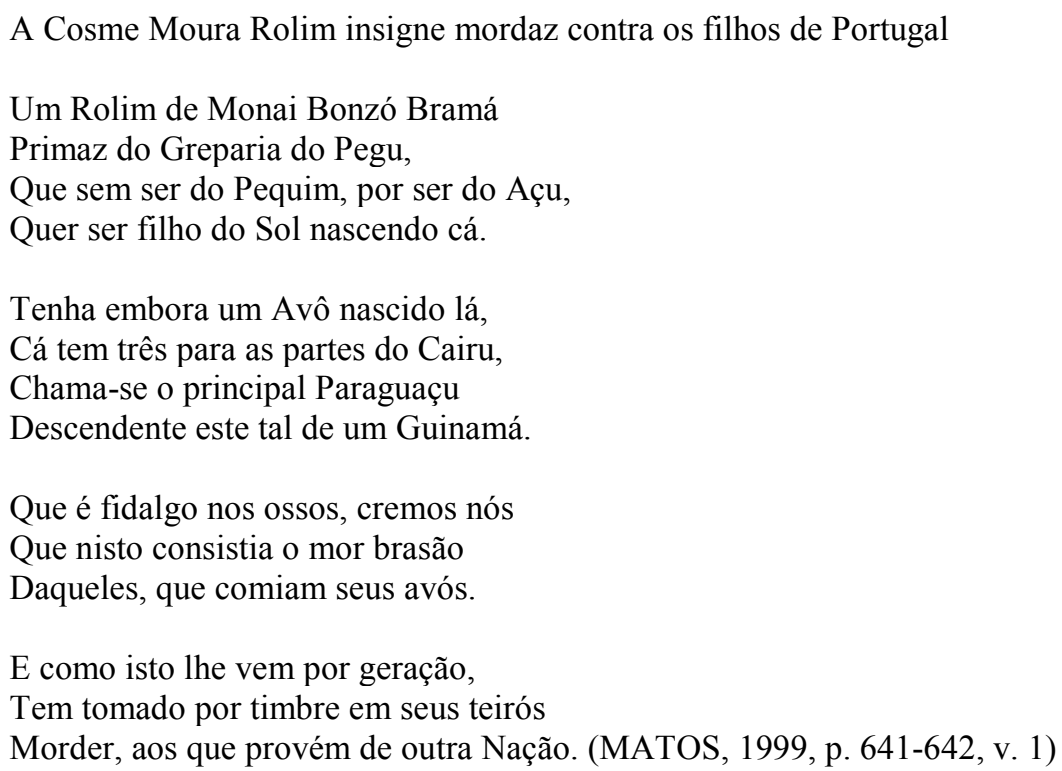

A cartilha da antropofagia ditava o repúdio ao elemento estrangeiro, mas o pai dessa mesma teoria foi ao estrangeiro buscar sua fonte inspiradora. Disso resulta a essência do Manifesto Antropófago, uma vez que o repúdio se dá no nível da submissão aos ditames estrangeiros. $\mathrm{O}$ que é bom é para ser devorado. $\mathrm{O}$ inimigo mais forte era devorado a fim de que sua força fosse assimilada pelo canibal, o que ocorre também na metáfora da eucaristia, onde o corpo e o sangue do herói imolado são ingeridos como representação da união entre os dois corpos, formando um só. Oswald de Andrade colheu do estrangeiro aquilo que era mais saudável e aqui, em solo brasileiro, soube aproveitar esse maná, dando-o fractalmente à sociedade brasileira. Em suma, rezava o Manifesto que a cultura brasileira não era inferior; podíamos exportar nossa cultura sem ter vergonha do olho alheio. Não parece lógico, mas o Manifesto é o avesso do discurso lógico, configurado num receituário para curar a peste que assolava o país no campo das artes. É o que afirma Benedito Nunes (1978, p. xxvi): “e esse remédio drástico, salvador, serviria de tônico reconstituinte para a convalescença intelectual do país e de vitamina ativadora de seu desenvolvimento futuro". Para ratificar essa informação, Augusto de Campos (1978, p. 124) nos afirma: “atitude crítica, posta em prática

compatriotas, e, o que é pior, a pretexto de piedade e religião) do que em assá-lo e comê-lo depois que está morto". (MONTAIGNE, 2010, p. 150).

Anu. Lit., Florianópolis, v. 21, n. 1, p. 46-57, 2016. ISSNe 2175-7917 
por Oswald, que se alimentou da cultura europeia para gerar suas próprias e desconcertantes criações, contestadoras dessa mesma cultura".

Se a História do Brasil se inicia com a devoração do bispo Pero Fernandes Sardinha, em 1554, significa que, desde então, vivemos sempre no ato antropofágico, expressamo-nos constantemente com a assertiva "Tupi or not tupi", a grande dúvida do homem barroco. A dúvida do príncipe Hamlet. $\mathrm{Na}$ verdade, Oswald de Andrade provoca essa conexão com o eterno processo de crise existencial, que é bem marcante no Barroco seiscentista e respinga na modernidade, no brado ecoante das vanguardas em solo brasileiro. A todo instante, os aforismos retomam o passado a fim de seduzi-lo e comê-lo. A esse respeito, Oswald de Andrade (1978, p. 77), citando Colombo, afirma:

\footnotetext{
Na expressão de Colombo, comían los hombres. Não o faziam porém, por gula ou fome. Tratava-ve de um rito que, encontrado também nas outras partes do globo, dá a idéia de exprimir um modo de pensar, uma visão do mundo, que caracterizou certa fase primitiva de toda a humanidade.
}

Comer a carne do outro, antes da antropofagia, era sinônimo de barbárie, selvageria, portanto, não servia como símbolo da cultura brasileira. Contra esse pensamento Oswald de Andrade se insurge pregando o contraponto, isto é, devolvendo ao mau selvagem, com seu rito canibalesco, o lugar de origem, ressignificando o pensamento sobre a cultura que deu origem ao Brasil. Para o colonizador, nós éramos a cultura do homem selvagem, da bestialidade e a teoria oswaldiana quer rebater esse preconceito, pois como afirma Nascimento (2011, p. 347) "a antropofagia designa preferencialmente o assim chamado latino-americano, como outro absoluto do europeu". Por isso, o teórico tenta superar o ufanismo romântico e o pessimismo idealista que tomou conta dos intelectuais. Com o intuito de resolver esses impasses, o olhar para o passado contribuiu para compreender todo o processo de formação da nossa identidade, principalmente rompendo com todos os modelos de colonização.

Nesse percurso teórico, “a operação metafísica que se liga ao rito antropofágico é o da transformação do tabu em totem" (CAMPOS, 1978, p. 122). Com influência de Freud, Oswald de Andrade traz para a teoria da antropofagia o percurso do parricídio canibalesco, que corresponde à morte do pai tirânico pelos filhos rebeldes e sua consequente devoração. E isso está aliado ao tema central da antropofagia, a redescoberta da identidade nacional. Ora, na sociedade primitiva evocada pelo antropófago Oswald de Andrade não havia um deus supremo, mas um homem totêmico que servia de ponte com o âmbito sagrado. Essa sociedade não vivia conflitos e contradições, não estava preocupada em dar explicações para as coisas 
da vida sob a intervenção de um Deus. O que nela havia era a crença na verdade que se sustentava pelos mitos. Por isso, prega-se a devoração dos tabus, aos quais está submetida a sociedade colonizada, que passou a querer explicar tudo, principalmente no estado agônico no qual o cristianismo vinha deixando o homem. Era preciso libertá-lo do sentimento de culpa do pecado do mundo, livrando-o da moral e da lógica do discurso religioso; em tese, prega-se o retorno à natureza. Uma natureza original, paradisíaca, abençoada por Pan. A proposta da antropofagia considera, nesse sentido, o estado natural da existência.

Ao inverter os papéis antropológicos do canibal, de bom a mau selvagem, Oswald de Andrade totemiza o tabu. Isto é, o mau selvagem, na devoração cultural, passa a ser objeto de culto, divinizado, sacralizado. O objeto proibido (canibal) é consagrado como símbolo brasileiro, que representará a discussão sobre a nacionalidade cultural brasileira, no sentido que está incutido na antropofagia, qual seja, a ideia de ancestralidade. Daí a necessidade de totemizá-lo, sobretudo, para romper com a cultura europeia que vinha deturpando a nossa, no sentido de explicar a verdadeira origem da nossa identidade nacional.

A antropofagia também é comunhão, que se reflete na conjugação do ato de comer, mastigando as partes para formar o bolo salutar que é a cultura brasileira. Ou seja, não é a antropofagia um elemento meramente desconstrutor, mas ressignifica o alimento digerido. $\mathrm{Na}$ metáfora moderna do liquidificador de significados se concentra essa comunhão. No liquidificador unem-se as partes díspares num todo ressonante, unicolor, o que facilita a digestão. Isso coloca Gregório de Matos na cena da produção poética imitativa que ele encenou nas ruas da Bahia barroca. Paul Valéry (apud BITARÃES NETTO, 2004, p. 28) diz que "nada mais original, nada mais intrínseco a si que se alimentar dos outros. Mas é preciso digeri-los. O leão é feito de carneiros assimilados". Gregório de Matos é um pouco de Gôngora, Quevedo, Cervantes, Camões, Lope de Vega, porque cada um desses, sendo partes digeridas, são integrados ao corpo que o absorveu.

A vida do poeta baiano é o reflexo do ato antropofágico. Tudo nele converge para o desregramento, para a ruptura, para o impacto. Seus versos satíricos, por exemplo, demonstram a dessacralização do tabu a fim de totemizá-lo. Exemplo disso são os muitos poemas em que a persona poética destroniza o poder instituído, exaltando o marginal. A linguagem empregada para ridicularizar os atores da cena poética está em perfeita consonância com a pregação da antropofagia. É, ademais, uma desconstrução alegórica do institucionalizado; das ruínas dessa destruição constrói-se a identidade brasileira. É como nos considera Bina Maltz (1993, p. 11) "destruir para construir em cima. Deglutir para, de posse 
do instrumental do 'inimigo', poder combatê-lo e superá-lo. Deglutir o velho saber, transformando-o em matéria-prima do novo". Se bem que a ideia de destruição é algo moderno e Gregório não estava preocupado com essa noção.

No percurso do Manifesto, Oswald de Andrade consagra o desnudamento do homem, a sociedade de roupas precisa despir-se das vestes "sagradas" do tabu para totemizar o corpo "sagrado" do homem, "o que atrapalhava na verdade era a roupa". Simbolicamente, Oswald dignifica o rompimento da mentira metaforizada pelas vestes do Velho Mundo e exalta a revelação da verdade que se vê estampada no corpo nu. A máscara da civilização deve cair diante do canibal. Observe-se como os jesuítas, no processo de catequese, deseducam os índios, fazendo-os vestirem roupas para as encenações ritualísticas. O jesuíta encobre o corpo nu do homem primitivo, encobrindo com isso a cultura, os costumes, as crenças, que, com a antropofagia, propõe-se descobrir, a fim de deixá-la exposta à verdade. Era justamente a nudez do indígena que causava estranhamento aos olhos do colonizador, que na descrição dos cronistas tem particular ênfase. Não há um texto em que não se perceba o tom de estranheza mediante a nudez primitiva. Por exemplo, Jean de Léry (1982, p. 64) assim considera: "coisa não menos estranha e de difícil de crer para os que não os viram, é que andam todos, homens, mulheres e crianças, nus como saírem do ventre materno. Não só não ocultam nenhuma parte do corpo, mas ainda não dão o menor sinal de pudor ou vergonha”. É nítido observar o juízo de valor que o europeu tem da vida do homem primitivo. Portanto, quando esse tipo de descrição chega ao continente europeu, causa rebuliço e interpretações que não poderiam ser diferentes das que nominam o nosso índio de selvagem. Lendo as descrições desses viajantes, encontramos a todo instante o índio sendo chamado de selvagem, isso porque observam pelo viés da religião católica, da moral cristã, dos costumes, da governança, da política, das artes. Daí o caráter preconceituoso com relação ao canibalismo. Esse preconceito também é observado em relação ao termo antropófago pelo filósofo francês, educado pelos jesuítas, nascido no fim do século XVII, Voltaire. O antropófago de Oswald de Andrade é bem diferente do de Voltaire. O filósofo comunga do pensamento de que o Velho Mundo é a nação civilizada e o Novo Mundo a selvagem. Seu discurso está cheio de ranços dessa visão préconcebida pelos europeus. A culpa é dos homens que primeiro enxergaram nosso continente e nossa gente, nossa terra. Foram eles quem primeiro ajuizaram a cultura ameríndia de bestial. Voltaire (2008, p. 91) assim discorre sobre as duas nações antagônicas:

As nações que chamamos civilizadas têm plena razão em não assar no espeto os inimigos vencidos, pois, se fosse permitido comer os vizinhos, logo devoraríamos nossos compatriotas, o que seria grande inconveniente para as virtudes sociais. Mas 
as nações que hoje são civilizadas não o foram sempre; todas elas foram durante muito tempo selvagens; e por causa do número infinito de revoluções por que tem passado este mundo, o gênero humano tem sido ora numeroso, ora raro.

Chamamos a atenção para aquilo que afirma o filósofo sobre as nações que antes eram selvagens e agora são civilizadas. A resposta do antropófago ao colonizador europeu veio com o parricídio canibalesco. Embora a visão do mau selvagem tenha sido levada ao Velho Mundo pela pena dos viajantes e cronistas, eles mesmos, nas suas descrições, apresentam o real motivo do ritual de canibalismo encontrado no solo americano, isto é, devora-se o inimigo para obter suas forças. E não era simplesmente matar para comer, para saciar a fome da tribo. Pelo contrário, a morte do inimigo seguia todo um ritual, que durava um certo tempo. Havia uma solenidade em que todos participavam, que ia desde a captura do guerreiro inimigo, passando pelo bom tratamento dado, até o ato em si de comê-lo. Quem descreve bem esse episódio é Jean de Léry (1982, p. 65): “Quando vão à guerra, ou quando matam com solenidade um prisioneiro para comê-lo, os selvagens brasileiros enfeitam-se com vestes, máscaras, braceletes e outros ornatos de penas verdes, encarnadas ou azuis, de incomparável beleza natural, a fim de mostrar-se mais belos e mais bravos". Bastava ter olhado com perspicácia para o caráter ritualístico da cena e não teríamos sido chamados de selvagens, negativamente, ou antissociais, bestas; seríamos vistos como Oswald de Andrade afirma na sua teoria da antropofagia.

Diante do que estamos discutindo, Gregório de Matos apresenta esse ideal de ruptura, muito embora conviva num ambiente ideológico marcado pela censura religiosa e pelo abuso de poder. Mas como antropófago, o poeta promove, estilisticamente, o amálgama linguístico e cultural. Em seus poemas, existe um diálogo permanente entre as línguas que havia na época: escreve em tupi, em português, em espanhol e também, em latim. A língua tinha um papel importante e ao se juntar às formas do falar ameríndio, aos termos castelhanos, aos vocábulos afronegroides, às ladainhas latinas em homenagem à Virgem, provoca um estado de tensão, um choque. É o recurso que o poeta barroco utiliza para, de forma especial, contribuir para a formação da identidade brasileira. A poesia do século XVII promoveu uma renovação da linguagem renascentista, como exemplifica Segismundo Spina ([1980?], p. 68), dizendo que "a frase seiscentista é a frase solta, curta ou desconjunta, subversiva das leis de gravidade do pensamento estabelecidas pela prosa do Renascimento".

Sob a metáfora do caldeirão ardente (a sociedade brasileira formada sob bases heterogêneas), Affonso Ávila (1994) afirma que essa sociedade assimila toda essa heterogeneidade que está presente no jogo poético de Gregório de Matos. Os elementos tão 
díspares dessas culturas em solo ameríndio são derretidos poeticamente a fim de fornecer dados à homogeneidade aparente da nova cultura. Gregório de Matos utiliza-se desse recurso, ou seja, do vocabulário inter/intra/entre línguas liquefeito para o barroco tropical, como bem explora Segismundo Spina ([1980?], p. 71): “no Brasil apenas incorporou ao seu vocabulário lexicográfico a contribuição tupi e africana, vivificada pelo caudal gírico e chulo do tempo e por uma linguagem figurada que aqui e ali fazia despontar o barroco tropical". Como exemplo desse caudal gírico, como num festejo alegórico, exalta a voz poética:

\title{
AOS PRINCIPAIS DA BAHIA CHAMADO OS CARAMURUS
}

Há cousa como ver um Paiaiá

Mui prezado de ser Caramuru, Descendente de sangue de Tatu, Cujo torpe idioma é cobé pá.

\author{
A linha feminina é carimá \\ Moqueca, pititinga caruru \\ Mingau de puba, e vinho de caju \\ Pisado num pilão de Piraguá. \\ A masculina é um Aricobé \\ Cuja filha Cobé um branco Paí \\ Dormiu no promontório de Passé. \\ O Branco era um marau, que veio aqui, \\ Ela era uma Índia de Maré \\ Cobé pá, Aricobé, Cobé Paí. (MATOS, 1999, p. 640)
}

As escolhas lexicais que compõem a cena poética fazem parte essencialmente do alfabeto colonial tupi-guarani, que para sua compreensão necessitará o leitor de uma vivência maior com esse universo semântico ou a ajuda de um dicionário técnico. Não há um verso no soneto que não tenha, pelo menos, um termo da língua tupi e/ou africana. Esse poema parece ser uma explicação da gramática tupi, porque a segunda quadra e o primeiro terceto falam de substantivos femininos em um e masculinos em outro.

Nesse poema, portanto, revela-se o rito antropofágico na devoração alegórica dessas palavras oriundas de línguas diferentes. Surge, mais uma vez, a metáfora tão usada pelo Tropicalismo do liquidificar os significados que, nesse caso, correspondem ao universo de palavras de línguas diferentes sendo liquefeitas, resultando num todo orgânico possível pelo trabalho poético com o qual está bem familiarizado Gregório de Matos. Razão perfeita para, mais uma vez, asseverar que Gregório de Matos é a expressão antropofágica brasileira.

\section{Conclusão}

Partindo das prerrogativas teóricas dos irmãos Campos, em especial, de Augusto de Campos, quem afirmou ser Gregório de Matos nosso primeiro antropófago, é que este artigo 
tomou forma, seguindo o prumo da teoria elaborada por Oswald de Andrade, a antropofagia, entendida como um processo sob o qual se concentra a deglutição do outro, no sentido da absorção dos valores alheios para inseri-los no universo cultural que o absorve. Baseando-se no rito canibalesco, em que o sangue e o corpo do guerreiro inimigo são devorados com o fim de absorver suas forças, Oswald de Andrade elabora uma teoria vanguardista que explica perfeitamente a formação da sociedade brasileira. O rito antropofágico também está presente, nessa perspectiva, na Eucaristia, em cujo simbolismo se concentra a absorção do corpo e do sangue do cordeiro imolado, portanto, compatível com o canibalismo.

A poesia barroca de Gregório de Matos está em perfeita consonância com o teatro da vida, fazendo encenar juntos, antropofagicamente, o índio, o negro, o português, o espanhol. É uma poesia que reflete o barroco tropical, um barroco das simbioses, das mutações, no qual os elementos dos trópicos se mesclam aos europeus; portanto, é uma poesia antropofágica.

O caráter polivalente dos versos gregorianos, nos quais podemos enxergar um período muito importante para a formação da identidade literária no Brasil, é a fonte para defender a hipótese de que ele foi nosso primeiro antropófago, que soube unir os elementos díspares de uma sociedade barroca, amalgamando-os para resultar no que hoje chamamos Brasil.

\section{Referências}

ALMINO, João. Por um universalismo descentrado: considerações sobre a metáfora antropófaga. In: ROCHA, João Cezar de Castro; RUFFINELLI, Jorge (Orgs.). Antropofagia hoje? Oswald de Andrade em cena. São Paulo: Realizações Editora, 2011, p. 55-62.

ANDRADE, Oswald de. Do Pau-Brasil à Antropofagia e às Utopias. Manifestos, teses de concursos e ensaios. 2. ed. Rio de Janeiro: Civilização Brasileira, 1978. (Obras Completas VI)

ÁVILA, Affonso. O lúdico e as projeções do mundo barroco. 3. ed. atual. comp. São Paulo: Perspectiva, 1994. 2t.

BITARÃES NETTO, Adriano. Antropofagia oswaldiana: um receituário estético e científico. São Paulo: Annablume, 2004.

CAMPOS, Augusto de. Poesia, antipoesia, antropofagia. São Paulo: Cortez \& Moraes, 1978. Arte final para gregório. In: . O anticrítico. São Paulo: Companhia das Letras, 1986, p. 85-93.

CAMPOS, Haroldo de. A arte no horizonte do provável. São Paulo: Perspectiva, 2010.

GELADO, Viviana. Poéticas da transgressão: vanguarda e cultura popular nos anos 20 na América Latina. Rio de Janeiro: 7letras; São Carlos, SP: EdUFSCar, 2006. 
LERY, Jean de. Viagem à Terra do Brasil. In: CRONISTAS e Viajantes. São Paulo: Abril, 1982. p. 63-84. Sel. de textos, notas, estudos biográficos, históricos e críticos e exercícios por Carlos Vogt. e José Augusto Guimarães de Lemos.

MALTZ, Bina Friedman. Antropofagia: rito, metáfora e Pau-brasil. In: FERREIRA, Sérgio et al. Antropofagia e Tropicalismo. Porto Alegre: Ed. Universidade/UFRGS, 1993, p. 9-39.

MATOS, Gregório de. Crônica do Viver Baiano Seiscentista. Obra poética completa, edição de James Amado. 4. ed. Rio de Janeiro: Record, 1999. 2v.

MONTAIGNE, Michel de. Sobre os Canibais. In: Os ensaios. Trad. De Rosa Freire D’Aguiar. São Paulo: Companhia das Letras, 2010. p. 139-157.

NASCIMENTO, Evando. A antropofagia em questão. In: ROCHA, João Cezar de Castro; RUFFINELLI, Jorge (Orgs.). Antropofagia hoje? Oswald de Andrade em cena. São Paulo: Realizações Editora, 2011, p. 331-361.

NUNES, Benedito. Antropofagia ao alcance de todos. In: ANDRADE, Oswald de. Do PauBrasil à Antropofagia e às Utopias. Manifestos, teses de concursos e ensaios. 2. ed. Rio de Janeiro: Civilização Brasileira, 1978, p. XI-LIII. (Obras Completas VI)

SPINA, Segismundo. A língua literária no período colonial: o padrão português, Gregório de Matos. Revista do Instituto de Estudos Brasileiros, São Paulo, n. 22, USP, [1980?], p. 61-75.

VOLTAIRE. Dicionário Filosófico. Trad. De Ciro Mioranza e Antonio Geraldo da Silva. São Paulo: Editora Escala, 2008.

[Recebido em janeiro de 2016 e aceito para publicação em abril de 2016]

\section{Gregório de Matos, our first anthropophagus}

Abstract: The exponential figure of Gregório de Matos has been subject of many theoretical discussions through the years. This survey, there are yet two antagonist points of view linked to Gregório de Matos, on one side, there some researchers who defend him, on the other, some of them attack him. The first ones say this poet from Bahia was the first literary voice in Brazil, from the Baroque basis, while the last ones say he is a merely plagiarist of the Spanish poets from the $17^{\text {th }}$ century, without a real contribution to the development of Brazilian Literature. This article, which is the result of a doctoral research, follows the perspective this poet is an anthropophagus-baroque, devouring cultures, with an active participation in the process of our cultural and literary identity. Anchored by the critical thinking of brothers Campos, our work seeks to analyze and discuss of the hypothesis that Gregório de Matos was our first anthropophagus, and you can see in his poetry the intrinsic characteristics the anthropophagus movement, designed by Oswald de Andrade, during the $20^{\text {th }}$ century.

Keywords: Anthropophagy. Gregório de Matos. Baroque.

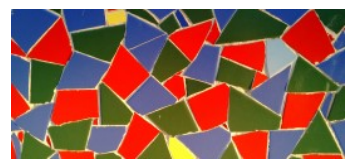

